\title{
Diagnostic Approaches: Images in GIM Acute Infectious Epiglottitis
}

\author{
Jeff Shrum MD and Ben J. Wilson BJ
}

\section{About the Author}

Jeff Shrum is a 5th-year general internal medicine subspecialty resident at the University of Calgary. Ben Wilson is a general internist at the Peter Lougheed Centre in Calgary, Alberta. Correspondence may be directed to Bjwilson@ucalgary.ca.

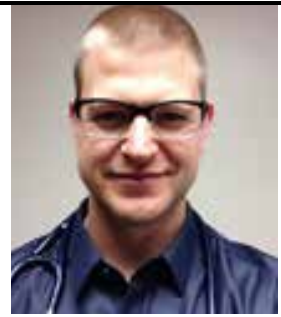

Shrum

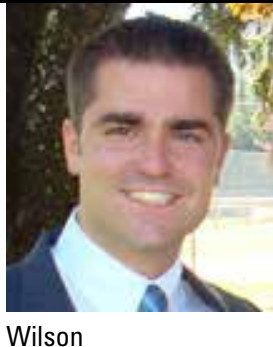

Wilson

\section{Case Report}

A 36-year-old man presented to the emergency department with 1 week of sore throat, odynophagia, change in voice and inability to swallow saliva. His oropharynx was unremarkable with no palpable cervical lymphadenopathy, but his anterior neck was tender to light palpation. Lateral cervical radiograph showed substantial epiglottal swelling manifesting as the 'thumb sign' (Figure 1). Bedside flexible nasal laryngoscopy revealed an erythematous edematous epiglottis, with preserved vocal cord structure and function. Acute infectious epiglottitis was diagnosed, and improved with intravenous antibiotics.

The thumb sign, as seen on lateral cervical radiograph, results from pathological enlargement of the epiglottis. ${ }^{1}$ Accurate data regarding the sensitivity of this sign is lacking. However, a retrospective review of 47 adult patients who presented at the emergency department with acute infectious epiglottitis found that $68 \%$ had the thumb sign. ${ }^{2}$

Direct visualization of an inflamed, edematous epiglottis is required for the definitive diagnosis of epiglottitis. Prior to widespread vaccination, acute infectious epiglottis was almost exclusively caused by Haemophilus influenza. ${ }^{3}$ Streptococcal species are now the most commonly isolated bacterial pathogen in adults. ${ }^{4}$

\section{References}

1. Podgore JK. The "thumb sign" and "little finger sign" in acute epiglottitis. J Pediatr 1976;88:154-155.

2. Qazi IM, Jafar AM, Hadi KA, et al. Acute epiglottitis: a retrospective review of 47 patients in Kuwait. Indian J Otolaryngol Head Neck Surg 2009;61:301-305.

3. Mayo-Smith MF, Spinale JW, Donskey CJ, et al. Acute epiglottitis: an 18-year experience in Rhode Island. Chest 1995;108:1640-47.

4. Briem B, Thorvardsson O, Petersen H. Acute epiglottitis in Iceland 1983-2005. Auris Nasus Larynx 2009; 36:46-52.

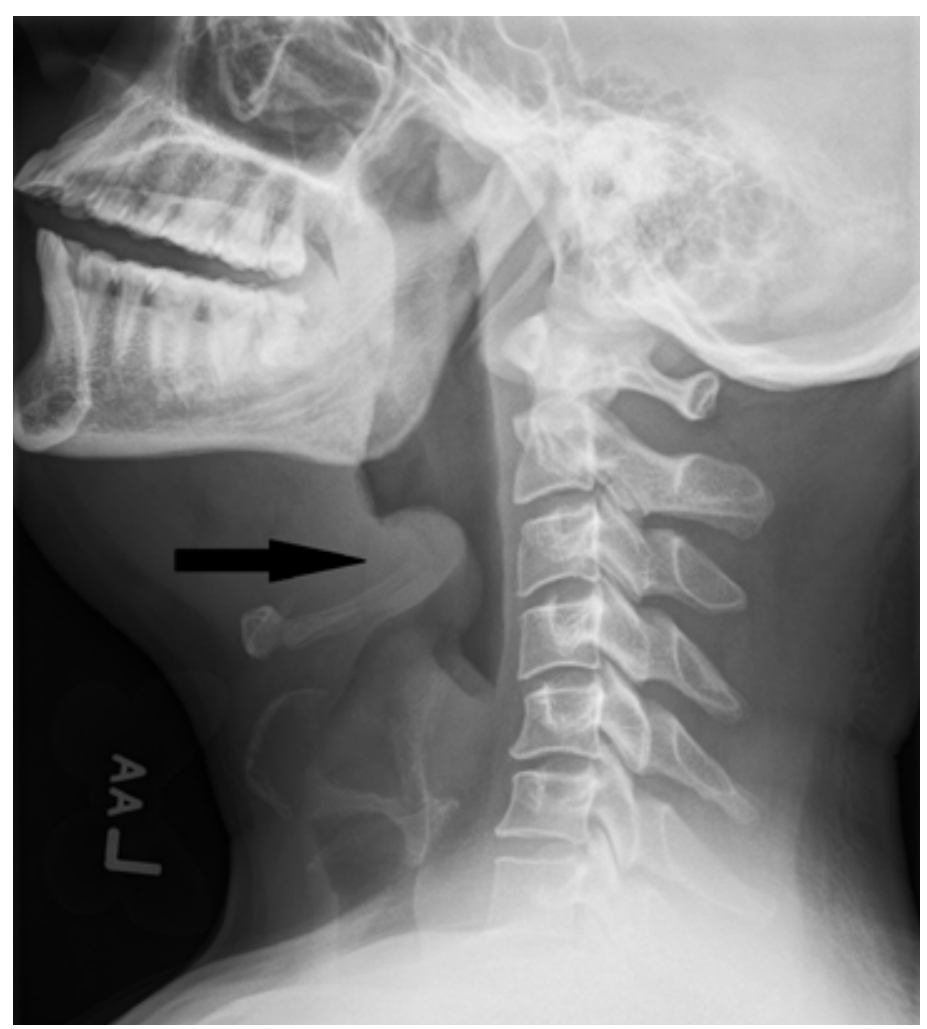

